\title{
THE AUSTRALIAN ANTS OF THE GENUS PRISTOMYRMEX, WITH A CASE OF APPARENT CHARACTER DISPLACEMENT ${ }^{1}$
}

\author{
By Robert W. TAYLoR \\ Biological Laboratories, Harvard University
}

\section{INTRODUCTION}

The Old World myrmicine ant genus, Pristomyrmex Mayr i 866, contains about 40 named forms, mostly from rain forests of the Ethiopian, Oriental and Australian regions. The Australian mainland fauna is small compared to that of New Guinea; it includes four species, three of which are newly described here. There are two species-groups, those of $P$. foveolatus $\mathrm{n}$. sp., and $P$. quadridentatus (André) 1905, each containing two species.

The former group includes $P$. foveolatus and $P$. thoracicus n. sp., closely related species with strong foveolate-reticulate sculpturation, having clear affinities with components of the New Guinean fauna, and known only from rain forests in the Cairns district of North Queensland. Foveolatus seems to be restricted to the Atherton Tableland, at elevations greater than IOOO $\mathrm{ft}$, while thoracicus is apparently more widespread, but is not known from the Tableland proper.

The affinities of the quadridentatus group are less clear; its species occur further south, in extreme S.E. Queensland, and N.E. New South Wales, and they may be derived from a separate, older, Melanesian stock. The group includes $P$. quadridentatus and $P$. wheeleri n. sp. Quadridentatus was originally placed in a separate monotypic genus, Odontomyrmex André 1905, which was synonymized with Pristomyrmex by Emery (1922). The lack of foveolate sculpturation on the head and body, and the presence of pronotal spines were thought by André to taxonomically characterize Odontomyrmex. But these characters occur together or separately in many Pristomyrmex species, and cannot be used to logically define a separate taxon (Brown, I953). Nonetheless the "Odontomyrmex" habitus seems to characterize a natural phyletic group within the Australian fauna, and quadridentatus and wheeleri are undoubtedly cognate, or at least closely related. The former species is typically self-colored golden-brown, but it has an apparently conspecific bicolored variant, quadridentatus variety

\footnotetext{
${ }^{1}$ Research supported by U.S. National Science Foundation Grant No. GB 1634 (1963-1965). Australian field studies in 1962, reported here, were supported by the Committee on Evolutionary Biology, Harvard University.
} 
queenslandensis Forel 1915, which is synonymized below. These two forms differ only slightly, except in coloration, and distributional evidence suggests that the bicolored form is a character-displaced variant, produced wherever the range of quadridentatus overlaps that of wheeleri (see fig. 15, plate 3 , and discussion on p. 53). Like their northern congeners the quadridentatus-group species are known only from rain forest, usually at elevations of + rooo $\mathrm{ft}$.

Available biological information is given in the taxonomic section to follow. Nesting apparently occurs in rotting logs in all species except wheeleri, colonies of which are usually located in the soil, under stones. Feeding and foraging behavior have not been extensively studied, but the bicolored form of quadridentatus forages nocturnally, in the open, on logs, tree trunks and low foliage. It appears that wheeleri may restrict its foraging activity to the soil and leaf litter, since strays have not been taken elsewhere, in spite of extensive search by the author.

All Australian Pristomyrmex types are workers, and the females are known for all species except foveolatus; I have seen no male specimens. Larvae of a North Queensland species were described by G. C. and J. Wheeler (1954). I have been unable to locate adults from the series involved; they would conform to the foveolatus-group diagnosis according to their collector, Dr. W. L. Brown, Jr.

This study is based on material from the Museum of Comparative Zoology collection at Harvard University, from Entomology Division, CSIRO, Canberra, The National Museum of Victoria, Melbourne, and the collection of Rev. B. B. Lowery, S.J., Sydney.

\section{MEASUREMENTS AND INDICES}

The following abbreviations are used in the descriptions below. Measurements were prepared using a stereomicroscope fitted with an eyepiece scale, reading directly in units of 0.1 and $0.01 \mathrm{~mm}$ at $100 \times$ magnification. The measurements cited are the maxima obtained after a series of trials, a fact of special importance when dealing with HL and WL.

HL Maximum head length, frontal view, from apex of median clypeal denticle to median occipital border.

HW Head width, frontal view, including the eyes.

$\mathrm{CI}$ Cephalic index $(\mathrm{HW} \times \mathrm{IOO}) / \mathrm{HL}$

SL Scape length, excluding articular boss and condyle (but including the expanded lamella at base of shaft).

SI Scape index (SL $>$ IOo)/HW

PW Pronotum width, anterior view, immediately below the bases of the pronotal spines. 
Scutum Width (females only), dorsal view, across the widest part of the sclerite.

WL Weber's length of mesosoma, lateral view; in worker, maximum diagonal distance from junction of anterior and dorsal faces of pronotum to apex of inferior metapleural lobe; in female, the anterior limit of measurement is the point where the pro-mesonotal suture meets the anterodorsal mesosomal profile.

Pronotal Spine $L$ (ength), as seen in PW measuring position, true vertical distance between base of spine on its mesial side, and the level of its apex.

Propodeal Spine L(ength), lateral view, maximum distance from apex of spine to opposite edge of propodeal spiracle.

Petiole $L$ (ength), lateral view, from tip of metapleural spine to posterodorsal edge of petiolar tergite.

Postpetiole Height, lateral view, maximum distance from apex of subpostpetiolar process to postpetiolar dorsum.

Eye Diameter, maximum diameter of eye.

Ocular Index (Eye Diameter $\times$ roo) $/ \mathrm{HW}$.

\section{Key to the Australian Pristomyrmex Species}

(Based on the workers)

I. Front of head, between the antennal scrobes, with numerous large shallow umbilicate foveae, their average diameter about 0.05-0.06 $\mathrm{mm}$ (group of $P$. foveolatus)

Area of frons between antennal scrobes entirely smooth, lacking sculpturation apart from a few minute, pilosity-bearing punctures (group of $P$. quadridentatus)

2. Scapes barely reaching level of occipital border when at rest in the antennal scrobes, with the head held in full-face view (fig. I ) ; Scape Index 78-83 $P$. foveolatus n. sp. Scapes exceeding level of occipital border by I-I.5 $\times$ their maximum thickness when at rest in the antennal scrobes, with the head viewed full-face (fig. 3), Scape Index 96-Ior

$P$. thoracicus n. sp.

3. Head relatively narrow (Cephalic Index 97-IO3) (fig. 7), either concolorous with mesosoma or much lighter in color (plate 3 ); pronotal spines, in side view, distinctly longer and stronger than those of propodeum (fig. 8) .............. P. quadridentatus (André) Head relatively much broader (Cephalic Index ino-i I6) (fig. II) and usually much darker in color than the mesosoma (plate 3 ); pronotal spines subequal in size to propodeal ones, or very slightly smaller (fig. I2) $P$. wheeleri n. so. 


\section{Species-level Taxonomy \\ I. Pristomyrmex foveolatus new species}

(Figs. I, 2)

Holotype worker. HL $0.84 \mathrm{~mm}$; HW $0.92 \mathrm{~mm}$; CI I Io; SL 0.75 mm; SI 8I ; PW 0.55 mm; WL 0.79 mm; Propodeal Spine L o.35 $\mathrm{mm}$; Petiole L $0.30 \mathrm{~mm}$; Postpetiole Height $0.30 \mathrm{~mm}$. General features as in figures I and 2. Mandibles with two adjacent strong acute apical teeth and a truncated basal one, separated by a broad, shallowly concave diastema. Clypeus with a median longitudinal carina, its anterior border with 5 obtuse denticles, the median and outer lateral ones largest. Antennal scrobes shallow, their ventral borders obscure. Occipital area of cranium enclosed dorsally and laterally by a fine arched carina. Scapes barely attaining level of occipital border when lying in the antennal scrobes, with the head viewed in HL measuring position (see p. 36). Funiculus with a 3 -segmented club, proportions of its segments as in Figure I. Eyes moderately large, maximum diameter $0.12 \mathrm{~mm}$, their anterior edges almost twice this distance from the anterior genal borders. Mesosomal profile as in Figure 2. Pronotum truncated anteriorly, its inferior angles edentate. Humeri each with a small acute tooth about 0.05 $\mathrm{mm}$ long, inclined dorsolaterally to project beyond the main lateral outline of the pronotum, when viewed from above. Posterolateral corners of pronotal dorsum forming blunt angles of about 90 degrees in dorsal view. Anterodorsal edge of mesepisternum extended anteriorly as a strong, moderately acute process which partially overlaps the fore-coxa. Propodeal spines long, almost straight, each diverging from the dorsal midline at an angle of about 20 degrees. Metapleural spines small, moderately acute, each about $0.07 \mathrm{~mm}$ long, slightly wider at base. Petiolar and postpetiolar profiles as in Figure 2. Petiole slightly narrower than postpetiole when viewed from above, its crest transverse in posterior view and feebly convex.

Mandibles generally smooth, with several longitudinal ribs. Clypeus strongly shining. Head polished and reflective, with numerous large shallow subcircular umbilicate foveae, averaging about $0.06 \mathrm{~mm}$ in diameter, largest on the posterior genal surfaces, lacking on a small smooth area between eye and antennal socket on each side, generally separated by distances averaging about one-third their mean diameter. Postgenae obscurely foveolate. Antennal scrobes smooth, with an almost effaced rugulosity and several arched transverse striae anteriorly. Pronotal dorsum obscurely foveolate, with several median longitudinal costulae. Posteriorly these meet a transverse carina which apparently represents the mesonotum. Propodeal dorsum smooth, 
framed by lateral and posterior carinae. Sides of mesosoma generally smooth, ventral parts of mesepisternum, metepisternal area, and sides of propodeum obscurely roughened. Petiole, postpetiole and gaster, antennae and legs, smooth and shining.

Pilosity moderately long and abundant on head and mesosoma, erect to sub-erect, longest on clypeus, crown of head, and pronotal dorsum; shorter erert hairs on scape, sub-erect ones on mandibles, funiculus and legs. Hairs lacking on sides of mesosoma. Petiolar and postpetiolar tergites each with three bilaterally symmetrical pairs of hairs (positions as in Figure 2), postpetiolar sternite with a single pair. Gaster very finely pilose apically, its first tergite completely bare. Pubescence lacking.

Color rich golden sienna-brown, mandibles, clypeus, antennae and legs lighter, eyes black, pilosity whitish.

Type-locality. Clump Point, west of Tully, N. Queensland.

The holotype was taken in a rotting wood fragment on the floor of very disturbed, depauperate rain forest, a few feet above sea level (June 25, I962; R. W. Taylor acc. I746).

Paratype workers. Three specimens collected with the holotype resemble it closely; they have the following dimensions: HL 0.82 $0.88 \mathrm{~mm}$; HW 0.87-0.96 mm; CI I06-I09; SL 0.72-0.75 mm; SI 78-83; PW 0.52-0.57 mm; WL 0.77-0.79 mm; Propodeal Spine L o.32-0.35 mm; Petiole L o.29-0.33 mm; Postpetiole Height 0.28-0.30 $\mathrm{mm}$.

An additional specimen from rain forest at Thornton Peak (Mt. Alexander), north-west of Daintree, N. Queensland (elevation not specified but probably + $1000 \mathrm{ft}$ (Darlington, 1960: i i 7), December 20-23, I957; P. F. Darlington) has: HL $0.85 \mathrm{~mm}$; HW $0.95 \mathrm{~mm}$; CI II 2; SL $0.75 \mathrm{~mm}$; SI 79; PW $0.53 \mathrm{~mm}$; WL $0.78 \mathrm{~mm}$; Propodeal Spine L $0.32 \mathrm{~mm}$; Petiole L $0.28 \mathrm{~mm}$; Postpetiole Height $0.29 \mathrm{~mm}$.

This species may show slight unimodal polymorphism. In the short series available SL, and the mesosomal dimensions $\mathrm{PW}$ and $\mathrm{WL}$ are negatively allometric relative to $\mathrm{HW}$, while $\mathrm{HL}$ is positively allometric.

Distribution and Material Examined. Known only from the five workers listed above. Clump Point and Thorton Peak are within the area of the main "base-of-peninsula" rain forest system of North Queensland.

Type deposition. Holotype and three paratypes in Museum of Comparative Zoology (MCZ) at Harvard University (Type No. 

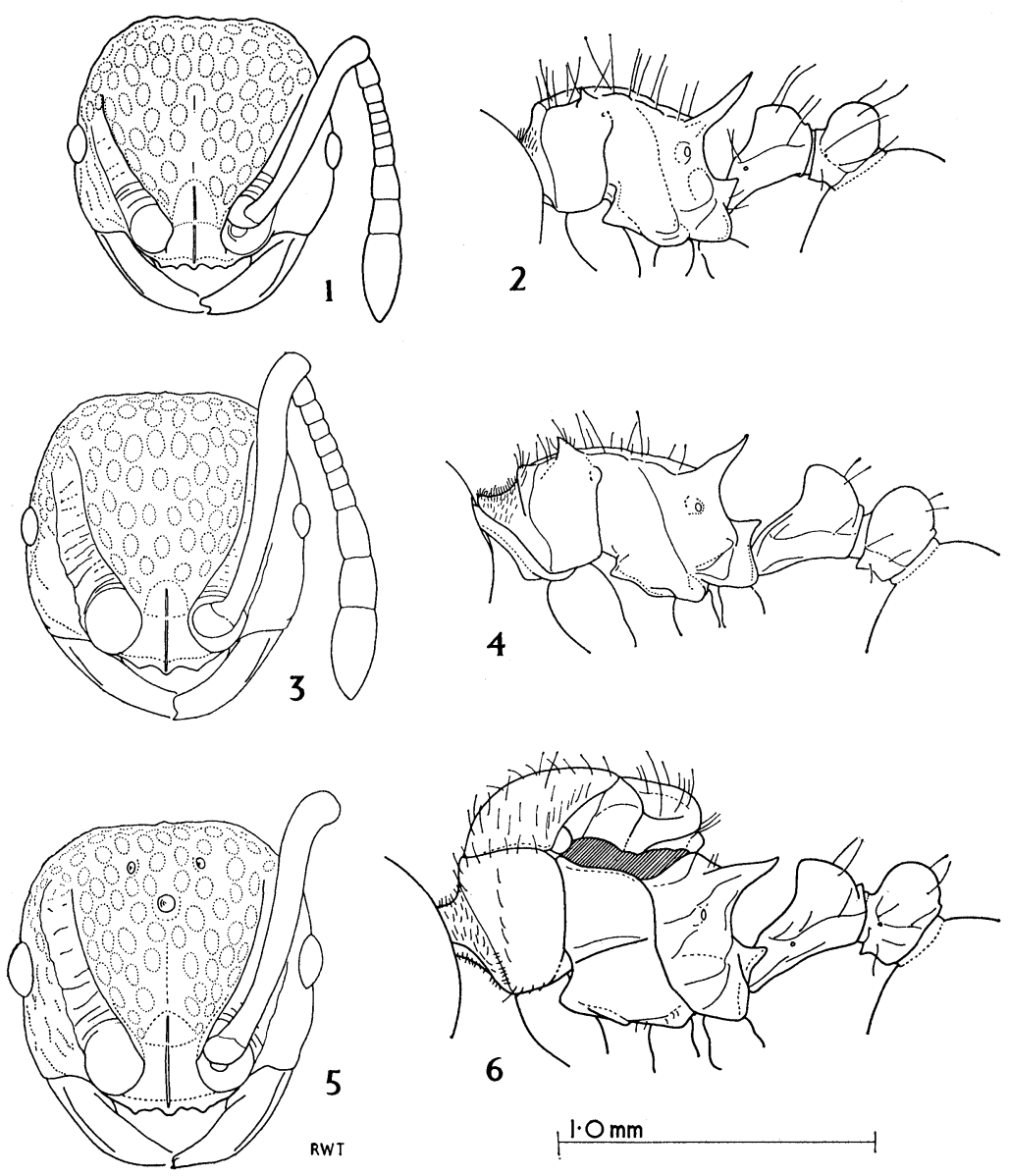

Figures 1-6: North Queensland species of Pristomyrmex foveolatus speciesgroup - $P$. foveolatus n. sp., holotype worker: fig. 1, head, frontal view; fig. 2, mesosoma, petiole and postpetiole, lateral view. - P. thoracicus $\mathrm{n}$. sp., holotype worker: fig. 3, head, frontal view; fig. 4, mesosoma, petiole and postpetiole, lateral view. Paratype female: fig. 5, head, frontal view; fig. 6, mesosoma, petiole and postpetiole, lateral view. 
3 I I52); one paratype (from Clump Point) in Australian National Insect Collection (CSIRO), Canberra.

\section{Pristomyrmex thoracicus new species}

(Figs. 3-6)

Worker. The following description is based on the holotype and I4 paratypes collected with it. Dimensions (holotype cited first) : HL 0.95, 0.89-0.96 mm; HW 0.95, 0.89-0.99 mm; CI 100, 98-104; SL 0.93, 0.90-0.96 mm; SI 98, 96-IOI; PW 0.49, 0.45-0.5 I mm; WL 0.9I, 0.87-0.94 mm; Propodeal Spine L 0.30, 0.28-0.32 mm; Petiole L 0.34, 0.33-0.36 mm; Postpetiole Height 0.32, 0.28-0.32 mm. General features as in Figures 3 and 4 . Similar to $P$. foveolatus, differentiated from it by the following characters:

I. Relatively narrow head (CI 98-IO5 against 106-I Io in foveolatus).

2. Much longer scapes, which surpass the level of the occipital border by I-I.5 $\times$ their maximum thickness when lying in the antennal scrobes, with the head viewed in the $\mathrm{HL}$ measuring position (SI 96-IOI against 78-83).

3. Proportionately much longer mesosoma (WL 0.94-I.00 $X$ $\mathrm{HW}$, against $0.8 \mathrm{I}-0.89 \times$ in foveolatus $)$, which is relatively very narrow (PW 0.5 I-0.53 $\times \mathrm{HW}$, and 0.50-0.55 $\times W \mathrm{WL}$ against $0.56-0.62 \times$ and $0.67-0.73 \times$ respectively in foveolatus $)$.

4. Eyes relatively slightly smaller; antennal scrobes more distinctly outlined. Humeral teeth more erect, failing to project beyond lateral pronotal outline when viewed from above. Posterolateral corners of pronotal dorsum obtuse, broadly rounded in dorsal view. Propodeal spines slightly sinuate, their apices turned upwards; diverging from the dorsal midline at angles of about 20 degrees. Metapleural spines more acute. Petiolar crest strongly convex in dorsal view, its outline almost a half circle.

5. Sculpturation virtually identical. Cephalic foveae a little more spaced; sides of mesosoma less sculptured, generally smooth and shining.

6. Pilosity similarly distributed, the hairs shorter, especially on the crown of the head, and the pronotal dorsum; less abundant on propodeal dorsum. Hairs of petiole, postpetiole and gaster placed exactly as in foveolatus.

Type-locality. Vision Falls, Lake Eacham National Park, N. Queensland. The type nest series was taken from a rotting log in rain forest, elevation c. $2500 \mathrm{ft}$ (June 6, 1962; R. W. Taylor acc. 1399). 
Additional paratype workers. Three workers from Beatrice River, Crawford's Lookout, N. Queensland (elevation probably c. IOOO ft. (Darlington, I960: I I8), rain forest, February 2I-22, I958; Darlingtons) and a single worker from Kuranda, N. Queensland ( I $100 \mathrm{ft}$, rain forest, July 4, I962, R. W. Taylor acc. I358) have the following dimensions (Crawford's Lookout material cited first) : HL 0.86-0.89, o.89 mm; HW 0.87-0.90, 0.93 mm ; CI IOI-I02, I05; SL 0.88-0.89, 0.90 mm; SI 99-IOI, 97; PW 0.45-0.47, $0.47 \mathrm{~mm}$; WL 0.84-0.85, $0.88 \mathrm{~mm}$; Propodeal Spine L 0.27-0.28, 0.3I mm; Petiole L o.3 I-0.33, 0.33 mm; Postpetiole Height 0.29-0.3 I, 0.3 I mm. Polymorphism weak, as in $P$. foveolatus - SL, PW and WL negatively allometric relative to $\mathrm{HW}$, HL positively allometric.

Paratype females. Two females are present in the type series, one from the holotype nest, the other from the Crawford's Lookout collection. Dimensions (Lake Eacham specimen cited first): HL 0.96, $0.95 \mathrm{~mm}$; HW I.04, I.02 mm; CI I09, I08; SL 0.95, 0.92 mm; SI 9I, 90; Scutum W 0.67, $0.65 \mathrm{~mm}$; WL I.09, I.04 mm; Propodeal Spine L 0.32, 0.3 I mm; Petiole L 0.38, $0.38 \mathrm{~mm}$; Postpetiole Height $0.35,0.35 \mathrm{~mm}$; Eye Diameter 0.17, 0.I $7 \mathrm{~mm}$; Ocular Index I6, I7. General features as in Figures 5 and 6 . Pronotum without humeral spines; mesoscutum lacking parapsidal lines, propodeal spines diverging from dorsal midline at angles of 30 and 33 degrees. Mesonotal sclerites moderately coarsely longitudinally costulate, with vestiges of interstitial foveae. Pilosity as in worker; petiolar and postpetiolar hairs similarly arrayed, the petiolar peduncle with an additional pair of lateral hairs.

Color as in worker; each ocellus with an adjacent black spot; the mesosomal suture lines darkly infuscated.

Distribution and material examined. Known only from the 19 workers and two females discussed above. Lake Eacham, Crawford's Lookout and Kuranda are all at moderately high elevations on the Atherton Tableland, within the compass of the main "base-ofpeninsula" rain forest system of $\mathrm{N}$. Queensland.

Type deposition. Holotype, I I paratype workers and paratype female (from holotype nest) in MCZ (Type No. 3II53); four paratype workers and female in CSIRO; single paratypes in Queensland Museum, Brisbane; National Museum of Victoria, Melbourne; and British Museum (Nat. Hist.), London.

\section{Pristomyrmex quadridentatus (Ern. André)}

$$
\text { (Figs. 7-IO, Plate 3) }
$$

Odontomyrmex quadridentatus Ern. André, 1905, Rev. Ent. Caen., 24: 207, worker. Type-locality: Sydney. 
Pristomyrmex quadridentatus: Emery, 1922, Gen. Ins., 174c: 234.

Pristomyrmex (Odontomyrmex) quadridentatus v. queenslandensis Forel, 1915, Arkiv F. Zool., 9 (16): 53, worker. Type-locality: Mt. Tambourine (=Tamborine Mountain). NEW SYNONYMY.

Pristomyrmex quadridentatus var. queenslandensis: Emery, 1922, Gen. Ins., $174 \mathrm{c}: 234$.

Syntype workers. Two quadridentatus syntypes, each labeled "Sydney/Duchaussoy/TYPE" have kindly been loaned for study by Mlle. S. Kelner-Pillault of the Muséum National D'Histoire Naturelle, Paris. These specimens are here designated lectotype and paralectotype and are so labeled. The paralectotype gaster is missing.

Judging from subsequent records the Sydney type-locality may be outside the true range of this species and should be regarded with reservation as a distributional record until confirmed.

Dimensions as given in Table I (lectotype cited first). General features as in Figures 7 and 8. Mandibular dentition as in $P$. foveolatus. Clypeus with a median longitudinal carina, its anterior border with three separated, moderately acute denticles (apparently representing the median and outer-lateral ones of foveolatus). Antennal scrobes open posteriorly but well defined dorsally and ventrally by distinct sharp sub-parallel carinae. Occipital carina distinct. Scapes, in frontal view, laid in the scrobes, exceeding the level of the occipital border by about I.5 $\times$ their maximum thickness. Funicular proportions as in Fig. 7. Ocular Index 17-18.

Mesosomal profile as in Figure 8. Pronotum with a distinct transverse anterior carina. Pronotal spines almost vertical, considerably stronger than propodeal ones. Mesonotum represented by a transverse carina on mesosomal dorsum. Propodeal spines each diverging from the midline at an angle of about 12 degrees; about equal in size to metapleural spines in lectotype, somewhat smaller in paralectotype. Petiole and postpetiole as in Figure 9; petiolar crest strongly arched in posterior view; postpetiole very slightly wider than petiole in dorsal view.

Head and body almost completely lacking sculpturation, smooth and strongly shining, except for a little fine shagreening on the pronotal collar and slight obscure roughening on the sides of the propodeum. Pilosity generally as in $P$. foveolatus; petiolar and postpetiolar hairs similarly distributed, but with an additional pair on the petiolar peduncle (as in the thoracicus female). First gastric tergite completely naked. Pubescence virtually absent.

${ }^{2}$ I have not seen the queenslandensis type, but specimens from the Mt. D'Aguilar series, listed below, have been directly compared with it for me by Dr. W. L. Brown, Jr. 

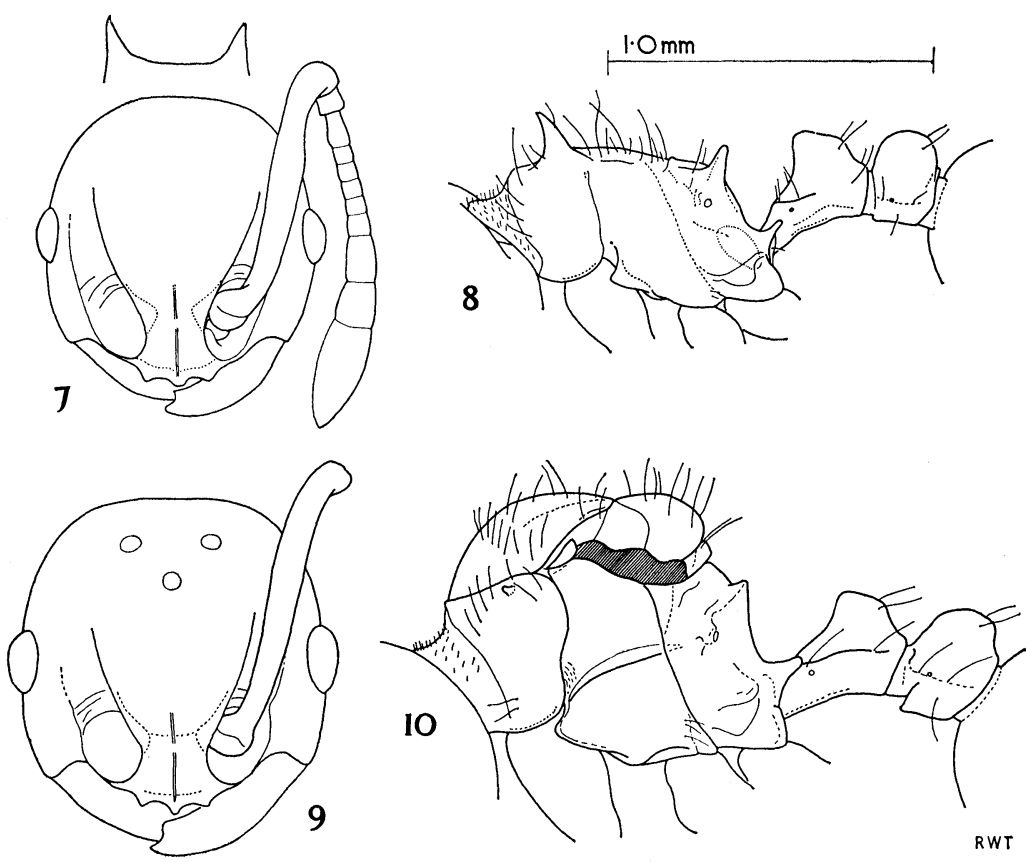

Figures 7-10: Pristomyrmex quadridentatus André.- lectotype worker: fig. 7, head and pronotal outline in frontal view; fig. 8, mesosoma, petiole and postpetiole in lateral view. Female (self-colored form): fig. 9, head, frontal view; fig. 10, mesosoma, petiole and postpetiole, lateral view.

Color almost even rich light-golden sienna-brown, mesosoma a shade darker, masticatory border of mandible, and segments 2-8 of antennal funiculus darkly infuscated, less dark infuscation on scapes and the various carinae and spines of head and mesosoma. Eyes dark brown, almost black.

Additional material examined, distribution. Additional distributional records fall into two geographical clusters (Fig. I5) which coincide with the distribution of two morphological forms, apparently representing geographical variants of a single species. These variants are discussed in detail below and illustrated in plate 3 ; essentially there is a southern, self-colored golden-brown form (to which the lectotype and paralectotype belong), and a more northern bicolored form with dark blackish-brown mesosoma, petiole and postpetiole (equivalent to Forel's suppressed variety queenslandensis). They are distributed as follows: 
I. Self-colored form: N.E. NEW SOUTH WALES between about S. lat. 29.40 and 30.20 (not including Sydney - see above) (open circles in Fig. I5).

Specific records are: Point Lookout to Grafton, dealate female, April 1958, (P. F. Darlington). New England National Park, Platypus Creek (elevation not given, probably 2-3000 ft - see LeGay Brereton, 1963, fig. I), in log, February 27, 1961 (Nicholls). The Dorrigo $3000 \mathrm{ft}$ (W. Heron).

2. Bicolored form: Extreme S.E. QUEENSLAND, between about S. lat. 27.20 and 28.20 (closed circles in Fig. 15).

Specific records are: Mt. D'Aguilar Range, $2000 \mathrm{ft}$, nest in rotting log, May 4, 1962 (RWT acc. 799). Cunningham's Gap, $2500 \mathrm{ft}$, nest in rotting log, May I, 1962 (RWT). Stradbroke Island, dealate queen, December 3, I9I2 (H. Hacker). Tamborine Mountain: no further data (A. M. Lea); Cedar Creek, ex rotting logs - dealate female, May 15, I95I, workers November I3, I950 and May I2, I95I (W. L. Brown); worker under log, February 27, 1956 (B. B. Lowery). Binna Burra: c. $2600 \mathrm{ft}$ : nests in rotting logs, one with alate female, May 22-23, I962 (RWT accs. II 45, I 82); several series of workers collected straying at night (see below under "ecology"), May 2I-23, 1962 (RWT). Lamington National Park, Coomera Gorge: leafmold berlesate, October 29, 1955 (T. E. Woodward) ; $2200 \mathrm{ft}$, nest in rotting log, May 23, 1962 (RWT acc. II68).

All the above records are specifically cited as rain forest collections, except the dealate female from Stradbroke Island, which has no ecological data.

Worker variation. Measurements and indices of workers from the above series are summarized in Table $I$. The similarity of ranges and means in the two color variants is obvious and reflects their considerable resemblance in all characters except color.

The coloration of the types (Plate 3, lower figure) is typical of the self-colored form. The bicolored form has the mesosoma, petiole and postpetiole very dark blackish-brown, contrasting sharply with the golden-brown head, gaster and appendages (Plate 3, middle figure), and the antennal infuscation is much less intense. The pronotum and postpetiole may be medium to dark reddish-brown, usually in the larger specimens of a given series. Such individuals are probably incompletely colored; since these areas are the last to become fully pigmented in callow specimens.

The mesosomal spines vary in thickness, length and inclination. The pronotal pair are typically longer and thicker than the propodeal ones, 


\begin{tabular}{|c|c|c|c|c|c|c|c|c|}
\hline \multirow[b]{2}{*}{ Series No. } & \multicolumn{4}{|c|}{ SELF-COLORED FORM } & \multicolumn{4}{|c|}{ BICOLORED FORM } \\
\hline & Types & 1 & 2 & Total & 3 & 4 & 5 & Total \\
\hline Number & 2 & 4 & 11 & 17 & 10 & 14 & 31 & 55 \\
\hline HL & $0.95,0.99$ & $\begin{array}{c}1.03-1.07 \\
(1.04)\end{array}$ & $\begin{array}{c}1.00-1.06 \\
(1.03)\end{array}$ & $\begin{array}{c}0.95-1.07 \\
(1.00)\end{array}$ & $\begin{array}{c}0.88-1.06 \\
(0.97)\end{array}$ & $\begin{array}{c}0.92-1.11 \\
(1.03)\end{array}$ & $\begin{array}{c}0.97-1.11 \\
(1.01)\end{array}$ & $\begin{array}{c}0.88-1.11 \\
(1.00)\end{array}$ \\
\hline HW & $0.95,1.00$ & $\begin{array}{c}1.01-1.06 \\
(1.04)\end{array}$ & $\begin{array}{c}0.97-1.06 \\
(1.03)\end{array}$ & $\begin{array}{c}0.95-1.06 \\
(1.00)\end{array}$ & $\begin{array}{c}0.88-1.03 \\
(0.97)\end{array}$ & $\begin{array}{c}0.92-1.12 \\
(1.03)\end{array}$ & $\begin{array}{c}0.89-1.14 \\
(0.98)\end{array}$ & $\begin{array}{c}0.88-1.14 \\
(0.99)\end{array}$ \\
\hline CI & 100. 100 & $\begin{array}{l}98-100 \\
(99)\end{array}$ & $\begin{array}{c}100-103 \\
(101)\end{array}$ & $\begin{array}{l}98-103 \\
(100)\end{array}$ & $\begin{array}{l}97-103 \\
(100)\end{array}$ & $\begin{array}{l}98-101 \\
(100)\end{array}$ & $\begin{array}{l}98-103 \\
(101)\end{array}$ & $\begin{array}{l}97-103 \\
(100)\end{array}$ \\
\hline SL & $0.90,0.93$ & $\begin{array}{c}1.01-1.06 \\
(1.04)\end{array}$ & $\begin{array}{c}1.00-1.03 \\
(1.01)\end{array}$ & $\begin{array}{c}0.90-1.06 \\
(0.97)\end{array}$ & $\begin{array}{c}0.88-1.04 \\
(0.97)\end{array}$ & $\begin{array}{c}0.87-1.09 \\
(1.02)\end{array}$ & $\begin{array}{c}0.86-1.15 \\
(1.01)\end{array}$ & $\begin{array}{c}0.86-1.15 \\
(1.00)\end{array}$ \\
\hline SI & $95, \quad 93$ & 100 & $\begin{array}{l}97-103 \\
(99)\end{array}$ & $\begin{array}{c}93-103 \\
(97)\end{array}$ & $\begin{array}{l}97-103 \\
(99)\end{array}$ & $\begin{array}{l}95-105 \\
(99)\end{array}$ & $\begin{array}{l}95-103 \\
(98)\end{array}$ & $\begin{array}{l}95-105 \\
(99)\end{array}$ \\
\hline PW & $0.46,0.50$ & $\begin{array}{c}0.48-0.53 \\
(0.51)\end{array}$ & $\begin{array}{c}0.48-0.52 \\
(0.50)\end{array}$ & $\begin{array}{c}0.46-0.53 \\
(0.49)\end{array}$ & $\begin{array}{c}0.43-0.50 \\
(0.48)\end{array}$ & $\begin{array}{c}0.44-0.53 \\
(0.50)\end{array}$ & $\begin{array}{c}0.45-0.56 \\
(0.50)\end{array}$ & $\begin{array}{c}0.43-0.56 \\
(0.49)\end{array}$ \\
\hline WL & $0.95,0.99$ & $\begin{array}{c}1.03-1.06 \\
(1.04)\end{array}$ & $\begin{array}{c}1.01-1.06 \\
(1.03)\end{array}$ & $\begin{array}{c}0.95-1.06 \\
(1.00)\end{array}$ & $\begin{array}{c}0.92-1.03 \\
(0.99)\end{array}$ & $\begin{array}{c}0.92-1.05 \\
(1.00)\end{array}$ & $\begin{array}{c}0.92-1.15 \\
(1.03)\end{array}$ & $\begin{array}{c}0.92-1.15 \\
(1.01)\end{array}$ \\
\hline$\frac{W L \times 100}{H W}$ & 100,99 & 100 & $\begin{array}{c}100-105 \\
(101)\end{array}$ & $\begin{array}{l}99-105 \\
(100)\end{array}$ & $\begin{array}{c}100-104 \\
(101)\end{array}$ & $\begin{array}{c}100-101 \\
(100)\end{array}$ & $\begin{array}{l}98-103 \\
(101)\end{array}$ & $\begin{array}{l}98-104 \\
(101)\end{array}$ \\
\hline$\frac{P W \times 100}{H W}$ & 48,50 & $\begin{array}{c}48-50 \\
(49)\end{array}$ & $\begin{array}{c}46-50 \\
(48)\end{array}$ & $\begin{array}{c}46-50 \\
(49)\end{array}$ & $\begin{array}{c}47-51 \\
(48)\end{array}$ & $\begin{array}{c}47-50 \\
(48)\end{array}$ & $\begin{array}{c}47-51 \\
(49)\end{array}$ & $\begin{array}{c}47-51 \\
(48)\end{array}$ \\
\hline$\frac{P W \times 100}{W L}$ & $48, \quad 50$ & $\begin{array}{c}47-50 \\
(48)\end{array}$ & $\begin{array}{c}46-48 \\
(48)\end{array}$ & $\begin{array}{c}46-50 \\
(48)\end{array}$ & $\begin{array}{c}47-50 \\
(48)\end{array}$ & $\begin{array}{c}47-50 \\
(48)\end{array}$ & $\begin{array}{c}47-51 \\
(48)\end{array}$ & $\begin{array}{c}47-51 \\
(48)\end{array}$ \\
\hline $\begin{array}{l}\text { Pronotal } \\
\text { Spine L. }\end{array}$ & $0.15,0.15$ & $0.17-0.19$ & $0.15-0.20$ & $0.15-0.20$ & $0.13-0.18$ & $0.13-0.17$ & $0.13-0.17$ & $0.13-0.18$ \\
\hline $\begin{array}{l}\text { Propodeal } \\
\text { Spine L. }\end{array}$ & $0.23,0.22$ & $0.18-0.20$ & $0.20-0.24$ & $0.18-0.24$ & $0.15-0.20$ & $0.16-0.19$ & $0.16-0.20$ & $0.15-0.20$ \\
\hline Petiole I. & $0.33,0.33$ & $0.34-0.37$ & $0.33-0.37$ & $0.33-0.37$ & $0.32-0.37$ & $0.30-0,37$ & $0.30-0.38$ & $0.30-0.38$ \\
\hline Postpet. H. & $0.32,0.33$ & $0.34-0.35$ & $0.33-0.37$ & $0.32-0.37$ & $0.32-0.35$ & $0.31-0.36$ & $0.28-0.35$ & $0.28-0.36$ \\
\hline
\end{tabular}

Table 1. Pristomyrmex quadridentatus André. Comparison of standard measurements (in $\mathrm{mm}$ ) and indices, yielded by specimens from all known series. Mean values italicized. The types are ostensibly from Sydney (but see text). Numbers in the "series" column refer to the following localities: 1. New England National Park; 2. The Dorrigo; 3. Mt. D'Aguilar; 4. Tamborine Mt.; 5. Binna Burra.

which are usually about sub-equal to the metapleurals. The bicolored form tends to have thicker pronotal and smaller propodeal spines than the self-colored form; but the overall variation is such that the available quadridentatus material cannot be divided into two sets, coextensive with the color-variants, on the basis of spinational characters. 
A weak negative allometric relationship between spine development and body size is evidenced; this is best marked in the bicolored form, probably because of its better representation in the study series.

Female (previously undescribed). Six female specimens are available for study; one self-colored, five bicolored.

I. Self-colored form. A single dealate labeled Point Lookout Grafton, N.S.W., has the following dimensions: HL I.05 mm; HW I.07 mm; CI I02; SL 0.98 mm; SI 88; Scutum W $0.68 \mathrm{~mm}$; WL I.20 mm; Propodeal Spine L $0.22 \mathrm{~mm}$; Petiole L $0.35 \mathrm{~mm}$; Postpetiole Height $0.39 \mathrm{~mm}$; Eye Diameter $0.22 \mathrm{~mm}$; Ocular Index $2 \mathrm{I}$. General features as in Figures 9 and IO. Pronotum with a partly broken fine, arched transverse carina, its humeri each with a low obtuse tubercle. Parapsidal lines of mesoscutum very obscure, essentially vestigial. Bases of propodeal spines connected by a transverse carina. Metapleural spines slightly longer and more acute than propodeal ones.

Color and pilosity as in worker, the ocelli each with an adjacent small dark brown spot, the mesosomal suture lines and axillary sclerites infuscated dark brown.

2. Bicolored form. Two dealate specimens from Mt. D'Aguilar Range, one each from Stradbroke Island and Tamborine Mt., and an alate from Binna Burra, have the following dimensions: HL 0.95-I.22 mm; HW 0.99-I.30 mm; CI I02-IO6; SL 0.94-I.I $8 \mathrm{~mm}$; SI 9I-95; Scutum W 0.62-0.85 mm; WL I.IO-I.42 mm; Petiole L 0.32-0.46 mm; Postpetiole Height 0.32-0.43 mm; Eye Diameter $0.19-0.26 \mathrm{~mm}$; Ocular Index 19-20. The smallest specimen is from Mt. D'Aguilar Range, the largest is the Binna Burra alate (which has a forewing length of $1.9 \mathrm{~mm}$, hindwing length of $\mathrm{I} .3 \mathrm{~mm}$ ). Distribution of indices in the series implies negative allometry of scape length and head length, relative to head width. Pronotal spine development variable, apparently negatively allometric, smallest specimen with a low obtuse tubercle, largest one with an almost imperceptible slightly raised convexity. Propodeal spines similarly variable, best developed in smallest individuals (about comparable to self-colored specimen), represented only by slightly raised propodeal corners in largest specimen. Characters otherwise as in self-colored form, with the scapes proportionately slightly longer.

Coloration as in worker, ocellar area darkly infuscated; pronotum and scutum reddish brown in the Binna Burra alate, which may be incompletely colored.

Ecologv. All detailed records of quadridentatus show that nests are usually located in rotting logs, a fact confirmed in the field by 
the author, and by the experienced Australian collector B. B. Lowery, S. J., (pers. comm.).

On May 2I-23, I962, I established that the bicolored form is probably an exclusively nocturnal forager. During 4 days of intensive collecting in rain forest near Binna Burra, workers were never encountered abroad from nests during the day. At night, however, 22 workers in seven samples were taken as strays, during about four hours total collecting. These specimens were all collected between two and six hours after sunset (the limits of the observation period), and all were in the open on the surfaces of widely separated rotting logs. Several further individuals were taken near the ground on tree trunks, and one was collected from foliage in a sweep-net. In several cases these individuals appeared to be following trails, but they were always well separated from each other, at distances of $14-20 \mathrm{~cm}$. The ants moved slowly, their rate of progress being estimated at $10-15 \mathrm{~cm}$ per minute. The nature of the food was not determined.

Relationships. See discussion on p. 35.

\section{Pristomyrmex wheeleri new species}

(Figs. I I-I 5, Plate 3)

Type workers. The following description is based on the holotype and numerous paratypes from all parts of the distributional range given below.

Dimensions (holotype cited first): HL I.I 4, 0.97-I.23 mm; HW I.26, I.04-I.40 mm; CI III, I08-II6; SL I.II, 0.92-I.I4 mm; SI 88, 8I-90; PW 0.60, 0.5 I-0.67 mm; WL ı.09, 0.89-1.20 mm; Pronotal Spine L 0.I7, 0.I5-0.20 mm; Propodeal Spine L 0.35, 0.27-0.39 mm; Petiole L 0.4I, 0.36-0.44 mm; Postpetiole Height $0.38,0.3 \mathrm{I}-0.43 \mathrm{~mm}$. General features as in Figures II and I2, and Plate 3 (upper figure). Similar to $P$. quadridentatus, as described above, but differing in the following features:

I. Generally larger size (HW I.04-I.40 mm, opposed to 0.88-I.I 4 $\mathrm{mm}$ in quadridentatus), with much broader head (CI IO8-I I6 against 97-I03), and lower Scape Index (8I-90 opposed to 93-IO5).

2. Inferior carina of antennal scrobe vestigial or absent.

3. Pronotal and propodeal spines longer and more slender, in side view approximately sub-equal in length; metapleural spines acute, rarely more than half as long as propodeals.

4. Pilosity similar, the body hairs thicker and longer, petiolar peduncle with a single hair on each side, first gastric tergite naked.

5. Color distinctive; head deep dark umber-brown. Mandibles, clypeus and antennae rich golden-brown. Remainder of body goldenbrown, much like the self-colored form of quadridentatus, but more 

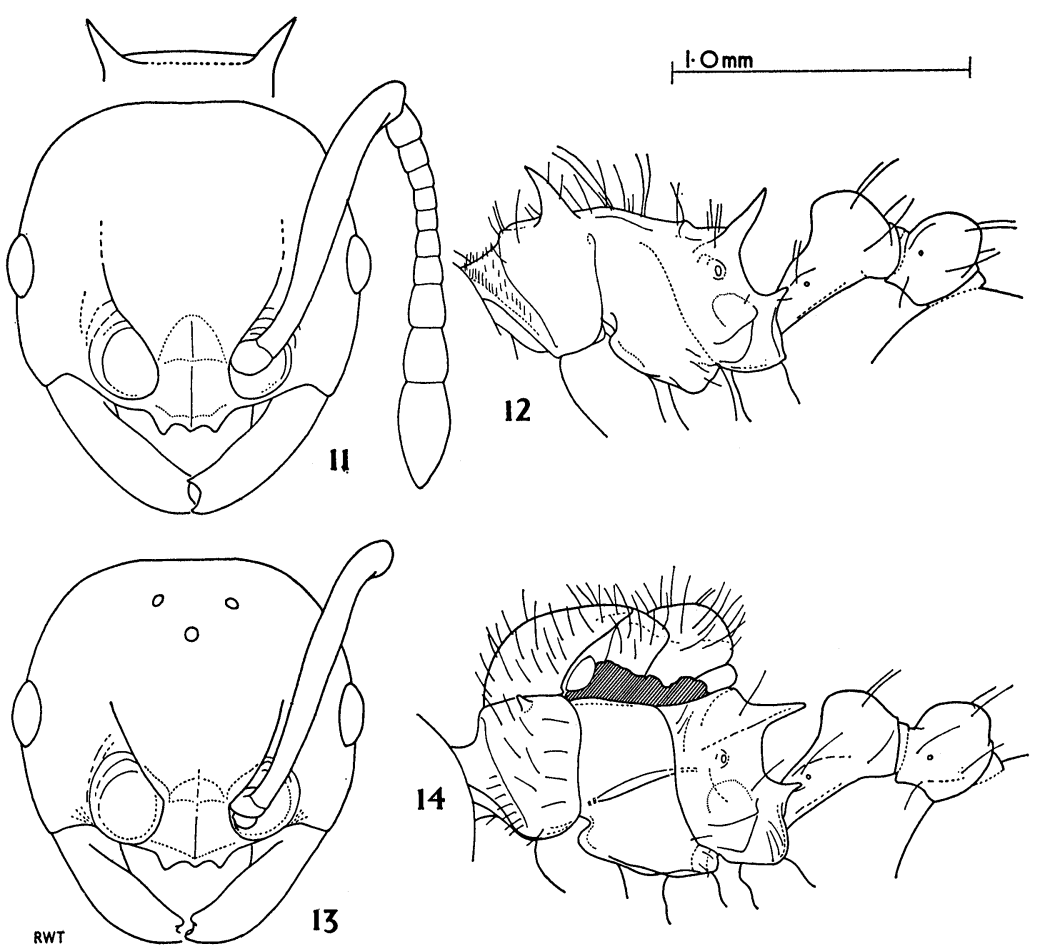

Figures 11-14: Pristomyrmex wheeleri n. sp. - Holotype worker: fig. 11, head and pronotal dorsum, frontal view; fig. 12, mesosoma, petiole and postpetiole, lateral view. - Paratype female: fig. 13, head, frontal view; fig. 14, mesosoma etc., lateral view.

yellowish. Posterior half of first gastric tergite shaded medium to dark reddish brown.

Type locality. Vicinity of Binna Burra, S.E. Queensland. The type colony was taken in soil under a stone in rain forest, elevation $c$. $2800 \mathrm{ft}$ (May 24, I962, R. W. Taylor acc. I28I).

Worker variation. Negative allometry of head length and scape length, relative to head width, is suggested by the distribution of cephalic and scape indices in the study series. Other characters, including the clypeal structure and the development of the mesosomal spines, show no apparently significant variation.

Paratype females. A female from the type-nest (cited first), and six others, one from each locality given below except National Park and Woodenbong, have the following dimensions: HL I.I I, I.I7I.25 mm; HW I.23, I.3I-I.42 mm; CI II2, II2-II4; SL I.04, 


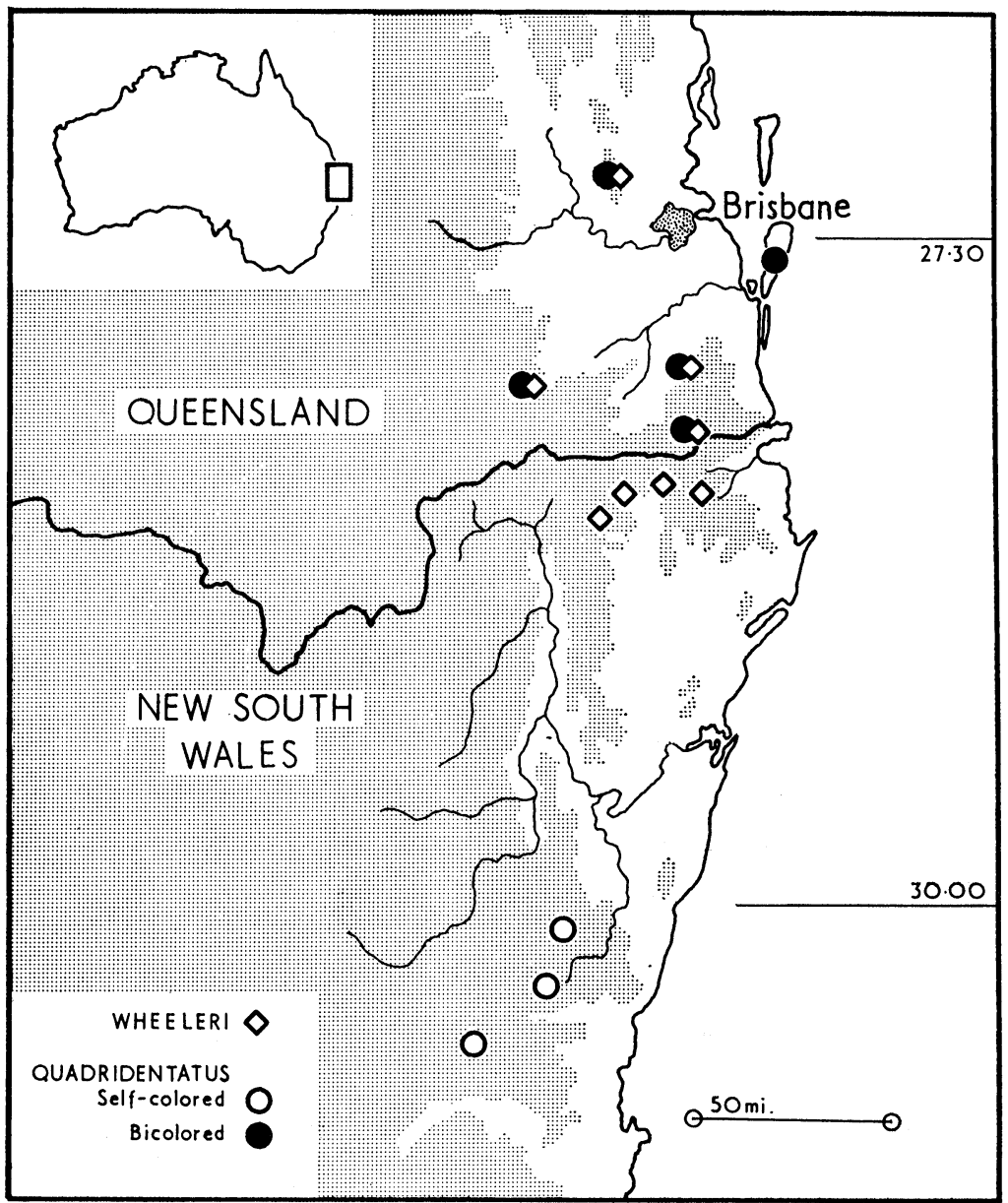

Figure 15 (above): Distribution of members of the Pristomyrmex quadridentatus group. Land above 200 meters elevation shaded.

EXPLANation OF PLATE 3 (opposite)

Workers of the Pristomyrmex quadridentatus group, to illustrate coloration. Top: P. wheeleri n. sp., from Binna Burra, S. E. Queensland. Middle: $P$. quadridentatus André, bicolored form, from Binna Burra (sympatric with wheeleri). Bottom: P. quadridentatus André, self-colored form, from New England National Park (Point Lookout) (allopatric with wheeleri). Author del. 

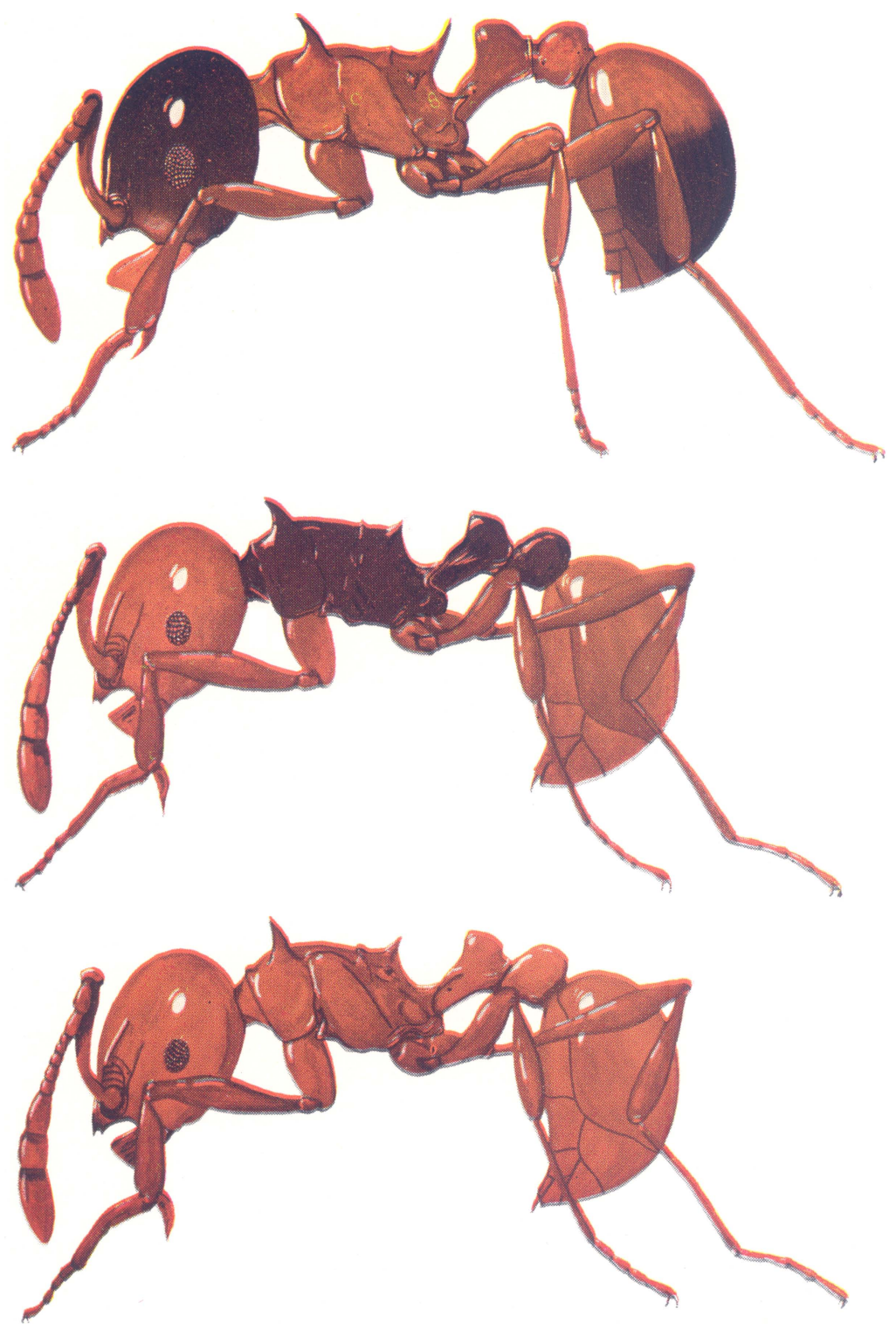

TAYLOR - PristomyrMeX 
I.08-I.12 mm; SI 85, 79-82; Scutum W 0.67, 0.78-0.84 mm; WL I.I9, I.26-I.36 mm; Propodeal Spine L 0.33, 0.35-0.39 mm; Petiole L 0.4I, 0.44-0.48 mm; Postpetiole Height 0.39, 0.4I-0.45 mm; Eye Diameter 0.24, 0.26-0.27 mm; Ocular Index 20, I9-20. Negative allometry of scape length and head length, relative to head width, is indicated. General features as in Figures 13 and I4. Distinguished from $P$. quadridentatus by very different proportions and coloration. Structure of clypeal apron variable, usually as in Figure I3; the median projection narrowed with reduced teeth in one specimen, bidentate in another, and completely edentate in a third. Transverse pronotal carina distinct. Pronotal spines variable, ranging from low rounded tubercles to small acute teeth (maximally about $0.03 \mathrm{~mm}$ long), with no apparent allometric tendency. Parapsidal lines feeble to moderately distinct. Propodeal spines almost invariable, their bases bridged by a low carina. Metapleural spines acute, distinctly shorter than propodeals.

Color and pilosity as in worker, mesosomal suture lines and alary sclerites infuscated dark brown.

Distribution and Material Examined. All records of $P$. wheeleri are from S. E. Queensland and N.E. New South Wales, between about S. Lat. 27.20 and 29.00 (Fig. I 5), as follows: QUEENSLAND: Mt. D'Aguilar Range, $2000 \mathrm{ft}$, colony, May 4, I962 (RWT acc. 8r9). Cunningham's Gap: $2500 \mathrm{ft}$, six colonies, January 22, I96I (B. B. Lowery) ; $2000 \mathrm{ft}$, colony, May I, I 962 (RWT acc. 72I). Tamborine Mountain: no further data (A. M. Lea); colony, January I5, I957 (B. B. Lowery); Curtis Falls, workers, leafmold berlesate, May 8, I953 (T. E. Woodward). Binna Burra: $2800 \mathrm{ft}$, colonies, May 21-25, I962 (RWT accs. I I92, I28 I (holotype nest series), I290, I293) ; stray, forest floor, 2 hours after sunset, May 23, I962 (RWT acc. I2 IO); 2600-3000 ft (P. F. Darlington). National Park, December I9r9 (H. Hacker). NEW SOUTH WALES: Woodenbong; Unumgar Forest, c. $2000 \mathrm{ft}$; Tooloom Range, c. $2000 \mathrm{ft}$, dealate female; all May I958 (Darlingtons). Mt. Warning, 2600-3000 ft, five colonies, September I3, I962 (B. B. Lowery).

Type deposition. Holotype and numerous paratypes (worker and female) in MCZ (Type No. 3II54), paratypes in CSIRO; Queensland Museum, Brisbane; Australian Museum, Sydney; National Museum of Victoria, Melbourne, and other Australian collections, also British Museum (NH), London, and B. P. Bishop Museum, Honolulu.

Ecology. All the above records are from rain forest. Sixteen of the 
I 8 colonies listed were found in soil under or between stones, one was in a rotting log (RWT acc. 819), and one in a rotting wood fragment (RWT acc. 72I). Nesting behavior thus contrasts with that of the sympatric bicolored form of quadridentatus, which has been found nesting only in rotting logs. Lowery's six Cunningham's Gap colonies each contained 18 to 36 workers and one queen. At Binna Burra I searched extensively for foragers of wheeleri but encountered only one (acc. I210), which was taken two hours after sunset on top of a small rock, later found to shelter a colony. Foraging behavior presumably is unlike that of $P$. quadridentatus (see p. 48 ).

Relationships. See below.

\section{DISTRIBUTION AND VARIATION IN THE QUADRIDENTATUS GROUP}

All known bicolored series of Pristomyrmex quadridentatus were collected in immediate geographical and temporal sympatric association with $P$. wheeleri, while the self-colored form has never been taken in such association. This correlation invites the hypothesis that character displacement of quadridentatus has occurred wherever the species is sympatric with wheeleri.

Character displacement is the situation, usually involving several related species, where interspecific differences are more distinct in areas of sympatry than in areas of allopatry. This phenomenon has long been recognized, but was first crystalized by Brown and Wilson (1956), who reported its occurrence in birds, frogs, fishes, crabs and various insects. Subsequent reports involve many animal groups, including the South African cyprinid fishes, Barbus marequensis and B. natalensis (Farquharson, 1962), the North American salamanders Plethodon cinereus (Green) and P. richmondi Netting and Mittleman (Highton, 1962), the Central American iguanids Basiliscus plumifrons Cope and $B$. vittatus Weigmann (Maturana, 1962), the East African gekkonids Holodactylus africanus Boettger and $H$. cornii Scortecci (Laurent, 1964), several pairs of Indian nuthatches of the genus Sitta (Ripley, 1959) and the New Zealand pelecypods Bassinia yatei (Gray) and B. parva Marwick, which apparently underwent displacement on becoming sympatric in the Lower Pleistocene (Fleming, 1959). Few of these cases have been studied in detail aimed at elucidating the selective significance of the displacement, though it seems clear that secondary reinforcement of premating isolating mechanisms, or special adaptation to greater niche specificity resulting from competitive displacement, are involved in some cases.

This hypothesis is invoked to explain the origin of the bicolored form of $P$. quadridentatus on limited distributional evidence, which needs supplementation. A selective mechanism is difficult to envisage since there is no evidence that color is involved in interspecific relations 
between these ants. Ecological differences between the sympatric forms are reported above; at Binna Burra quadridentatus nests in logs and forages openly at night, while wheeleri nests under stones and apparently forages cryptically. Nothing is known of the behavior of self-colored quadridentatus and such information is required. Bicolored quadridentatus and wheeleri are perhaps the most spectacularly colored members of their genus; their coincident distribution suggests that the causal factors producing their color patterns may be inter-related. The two "forms" of quadridentatus might prove ultimately to be good biological species, but even if this is the case, character displacement need not be rejected in explaining their color differences. These ants are worthy of much further study.

Brereton, J. LeG.

\section{LITERATURE CITED}

1963. Point Lookout survey New England National Park. Aust. J. Sci., $26(1): 10-14$.

Brown, W. L., JR.

1953. Characters and synonymies among the genera of ants, Part I. Breviora, $11: 1-13$.

Brown, W. L., JR., and E. O. WILson

1956. Character displacement. Syst. Zool., 5: 49-64.

Darlington, P. J., JR.

1960. Australian carabid beetles IV. List of localities, 1956-1958. Psyche, 67(4): 111-126.

EMERY, C.

1922. Formicidae, Subfamily Myrmicinae. Genera Insect., 174c: 207397.

Farquharson, F. L.

1962. The distribution of cyprinids in South Africa. Ann. Cape Prov. Museums, 2: 233-251.

Fleming, C. A.

1962. Paleontological evidence for speciation preceded by geographic isolation, in The Evolution of Living Organisms, G. W. Leeper

Highton, R. ed. pp. 1-459, Melbourne University Press, (pp. 225-241).

1962. Revision of North American salamanders of the genus Plethodon. Bull. Florida. State Mus., 6(3) :235-367.

LAURENT, R. F.

1964. Déplacement des charactères dans le genre Holodactylus (Reptilia, Gekkonidae). Senck. Biol., 45 (3/5): 417-423.

Maturana, H. R.

1962. A study of the species of the genus Basiliscus. Bull. Mus. Comp. Zool., Harv., $128(1)$ : 1-33.

RIPLEY, S. D.

1959. Character displacement in Indian nuthatches (Sitta). Postilla, Yale, 43 : 1-11.

Wheeler, G. C., and Jeanette Wheeler

1954. The ant larvae of the myrmicine tribe Myrmecinini. Proc. Ent. Soc. Washington, 56(3): 126-138. 

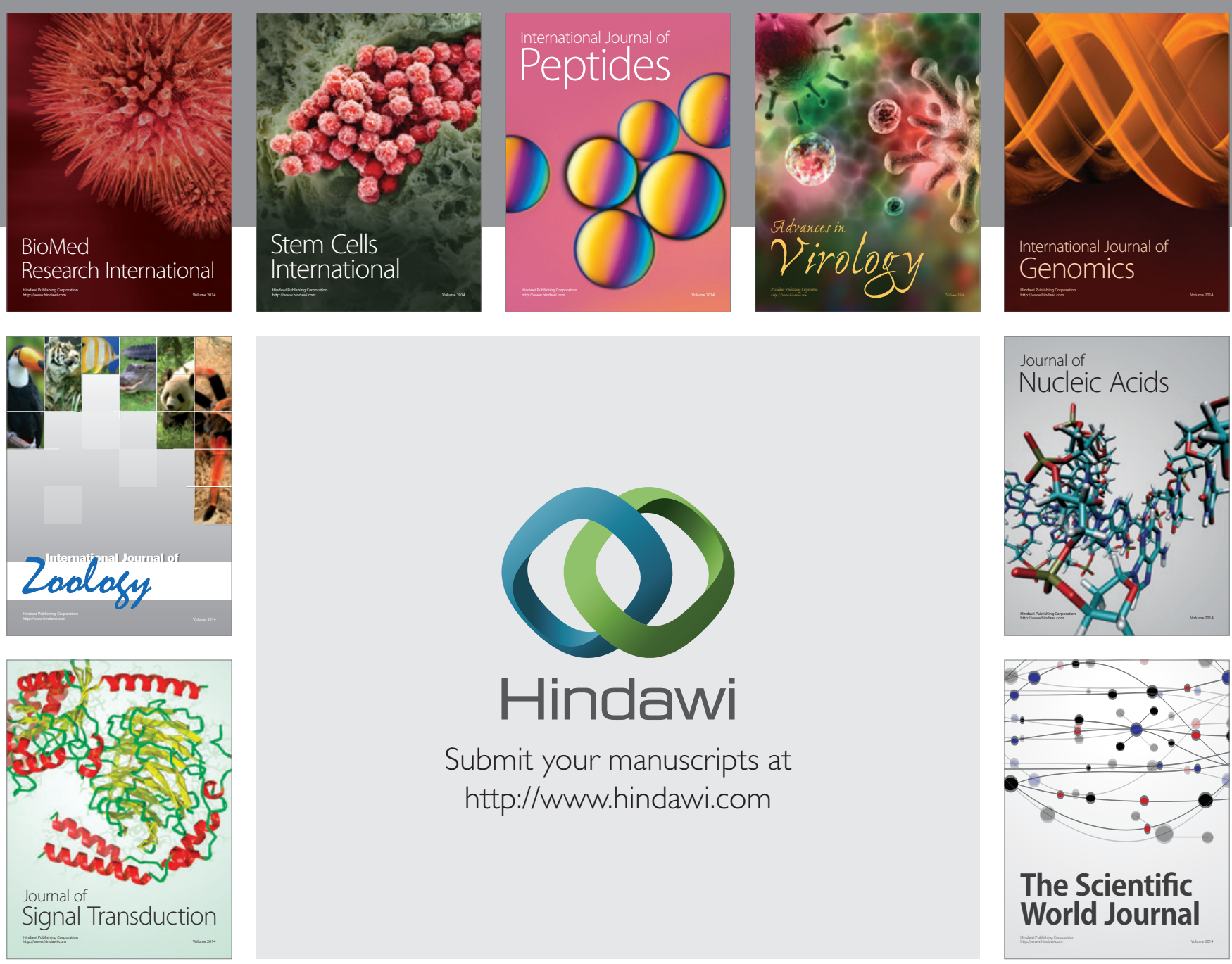

Submit your manuscripts at

http://www.hindawi.com
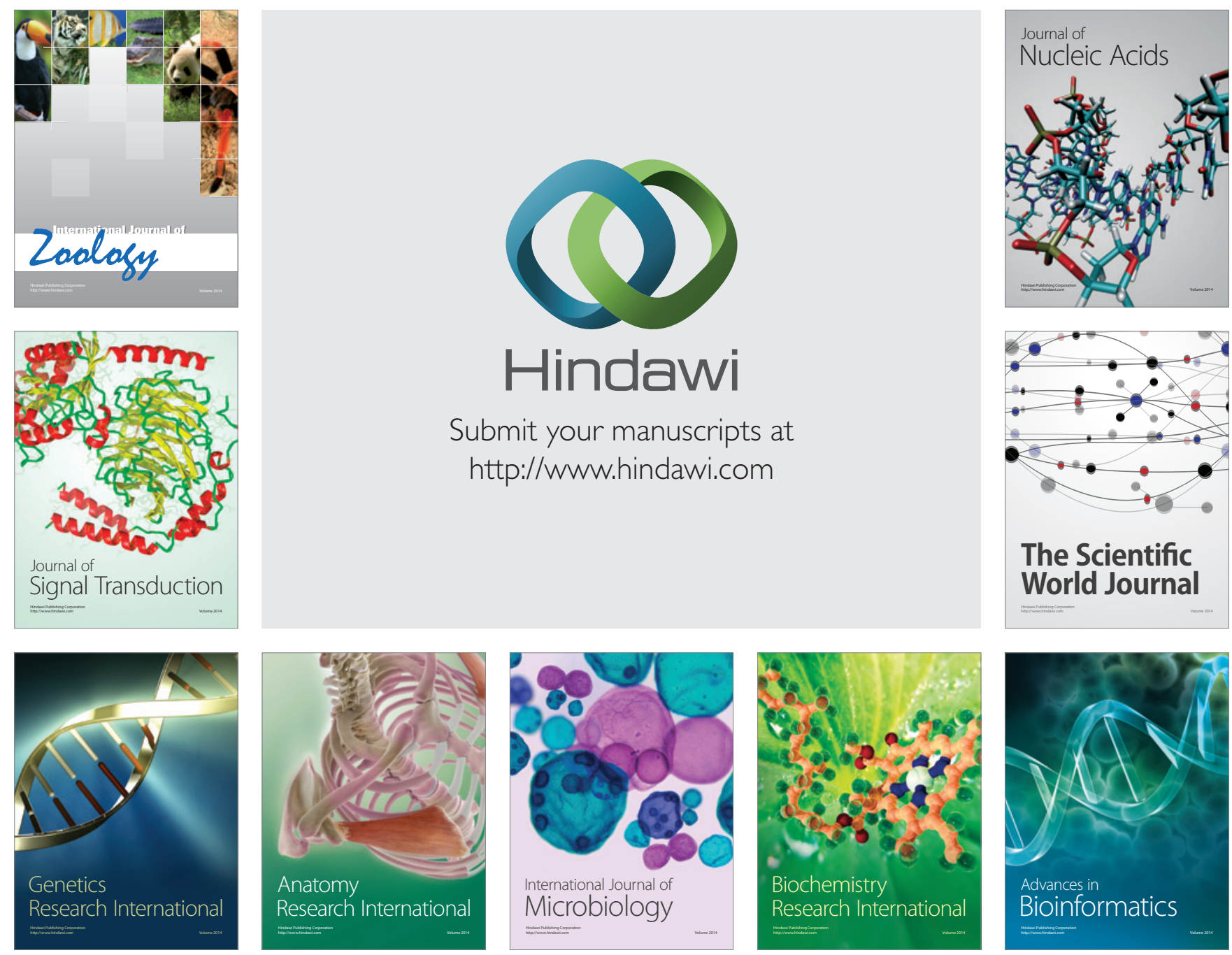

The Scientific World Journal
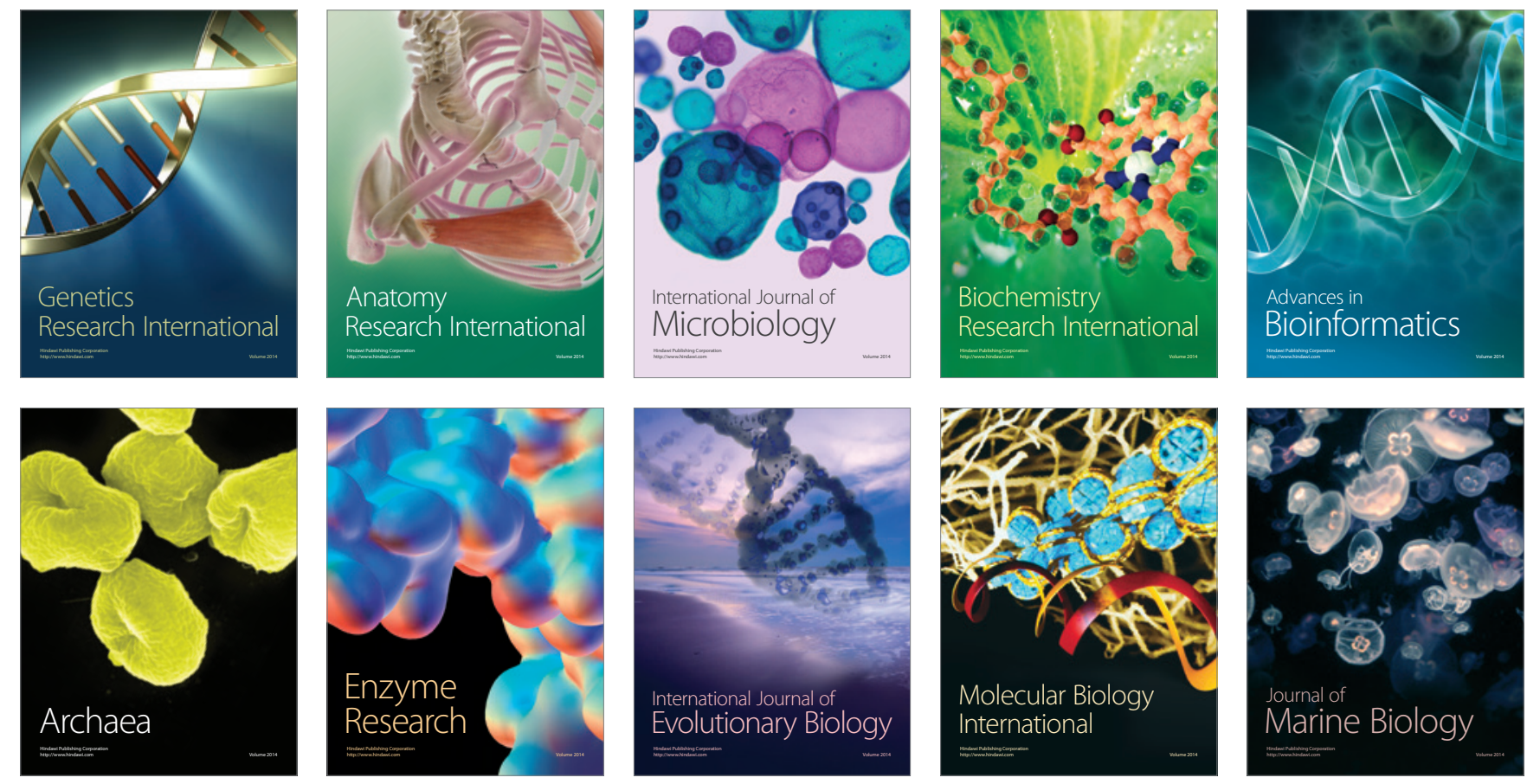